\title{
Scientist Citizens
}

\section{Rhetoric and Responsibility in L'Aquila}

Pietrucci, Pamela; Ceccarelli, Leah

Published in:

Rhetoric \& Public Affairs

DOI:

10.14321/rhetpublaffa.22.1.0095

Publication date:

2019

Document version

Publisher's PDF, also known as Version of record

Document license:

Unspecified

Citation for published version (APA):

Pietrucci, P., \& Ceccarelli, L. (2019). Scientist Citizens: Rhetoric and Responsibility in L'Aquila. Rhetoric \& Public Affairs, 22(1), 95-128. https://doi.org/10.14321/rhetpublaffa.22.1.0095 


\title{
Scientist Citizens: Rhetoric and Responsibility IN L'AQUILA
}

\author{
Pamela Pietrucci and Leah Ceccarelli
}

In this essay, we analyze the public communication debacle before the 2009 L'Aquila earthquake that led to the infamous trial of the "L'Aquila Seven." Examining the trial transcripts to extract norms regarding the proper role of scientists in society, we conclude that the first verdict interpellated the figure of the responsible scientist citizen who is expected to perform rhetorical citizenship when communicating with a lay public, while the second assumed a distinction between public and technical spheres that absolves scientists from responsibility to their fellow citizens and reduces their role to performance of an expertise divorced from rhetoric. Tracing the civic outcomes of these conflicting norms, we identify three missed opportunities during the prequake discourse in which the scientists failed to correct statements that they, and only they, knew to be flawed. To prevent future communicative debacles that arise from a dangerous separation of scientists and laypeople, we argue that scientists need to come to see themselves as scientist citizens, experts who take on the civic responsibility of clearly communicating their knowledge to their fellow citizens when such sharing is necessary to the public good.

Pamela PietrucCi is Assistant Professor in the Section of Rhetoric, Department of Media, Cognition and Communication at the University of Copenhagen, Denmark. LEAH CECCARELLI is Professor of Communication at the University of Washington in Seattle. 


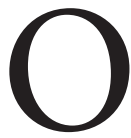

n October 22, 2012, six scientists with expertise in seismology and one official with Italy's Department of Civil Protection (DCP) were sentenced to six years in prison, after being convicted of negligence and manslaughter. The sentence condemned their communication failures during and immediately after an extraordinary meeting of Italy's Major Risks Commission (MRC) that had taken place in L'Aquila, the capital of the Abruzzo region in central Italy, five days before the destructive earthquake that hit that town on April 6, 2009. That emergency gathering had been publicized through a local press release that said the invited seismologists would gather in L'Aquila with the "goal of providing the citizens of Abruzzo with all the information available to the scientific community on the seismic activity of the last few weeks." ${ }^{1}$ In his verdict, Judge Marco Billi argued that the six scientists were not only negligent for conducting a hasty and grossly inadequate risk assessment, but they were also guilty on the manslaughter charges for having provided "imprecise, incomplete, and contradictory information" to the public in L'Aquila. Their negligence in not "informing the public with clear, correct and complete information"-according to the judge-resulted in the disastrously reassuring (and flawed) public perception that the many seismic shocks that had plagued the region could be considered a "favorable" dissipation of seismic energy, which reduced the likelihood of a more destructive event. ${ }^{2}$

According to the judge, that reassuring interpretation of the seismic swarm, reported to the public by the DCP official as being the definitive outcome of the scientific meeting, helped to persuade many residents of L'Aquila that their folkloric cautionary practice of escaping their homes to spend a few hours outside after medium intensity shocks was not only unnecessary but also quaintly irrational. After hearing the reassuring message of the expert meeting, they abruptly interrupted that traditional practice. Five days later, a number of those who chose to stay indoors after two moderate shocks hit the town on the night of April 5 were killed or badly injured in collapsing buildings when the disastrous quake struck in the early morning hours of April $6 .^{3}$

Two years after the manslaughter verdict, an appeals court in Italy overturned the decision, acquitting the scientists and only upholding the conviction of Bernardo De Bernardinis, the DCP official with no expertise in seismology who addressed the public to report the conclusions of the MRC meeting. Among the reasons given for this reversal upon appeal was 
the claim that the scientists of the MRC did not have a responsibility to communicate to the public. ${ }^{4}$ Appearing to follow a standard purification strategy that separates technical sphere from public sphere, and thus divides risk analysis from risk communication, the three-judge appeals panel ruled that the faulty public communication was De Bernardinis's fault alone. ${ }^{5}$

Putting aside the legal reasoning in this case, which we do not have the authority or inclination to contest, we think that the civic, ethical, and rhetorical outcome of this decision is troubling. While we are not in favor of imprisoning scientists, we think it is a bad idea to completely absolve the scientists from responsibility for the failed public communication in L'Aquila. As we will show, there were at least three occasions when the scientists who participated in the MRC meeting in L'Aquila had an opportunity to act not only as scientists but also as rhetorical citizens capable of correcting the misinformation that De Bernardinis conveyed to the public. Looking at this case through Christian Kock and Lisa Villadsen's notion of rhetorical citizenship, we demonstrate that "there is a need for rhetoric in a deliberative democracy" and that what is meant by rhetoric is "not just discourse by public officials or candidates." For scientists—who dwell in the public sphere like every other citizen-rhetorical citizenship includes evaluating and correcting the public rhetoric that is offered in their name, as a summary of their expert assessments. In fact, this is a mode of civic engagement that is available only to them. The public communication debacle in L'Aquila did not happen because the scientists failed to engage enough in their expert assessment during the meeting. Rather, it happened because they failed to engage as rhetorical citizens who had relevant expertise in relation to the public communication that circulated in L'Aquila around the MRC meeting. As Kock and Villadsen remind us in their discussion of rhetorical citizenship, in contemporary society "it also becomes increasingly urgent that citizens themselves take part in public exchange that invokes not only segment interests but also the common good." In L'Aquila, the scientists of the MRC were the only citizens capable of rectifying the flawed information that De Bernardinis passed to the local residents, and they repeatedly failed to enact that civic task-neglecting the common good by failing to actualize the power of their rhetorical agency as scientist citizens.

They failed to do so on at least three occasions: in the meeting itself when the incorrect claim about energy dissipation was raised as a subject for 
discussion, at the end of the meeting when a public official made a comment that indicated her misunderstanding of the science, and during the public communication after the meeting, particularly during the press conference, where the presence of MRC experts sitting with De Bernardinis conveyed their tacit assent to his disastrous reassurances. Absolving the scientists from responsibility for their lack of communication during these moments fosters the reoccurrence of such communicative failures in the future by segregating scientists from the larger community of which they are part.

Carolyn R. Miller has argued that the separation of risk analysis from risk communication, while commonly assumed by those who practice both, "is a false distinction" because "risk analysis is a form of communicating about risk." "We agree. We take her claim in a different direction, though, by emphasizing that experts in a scientific field who engage in risk analysis are responsible for conveying the results of their work to nonexperts, whether they do so by speaking directly to the public or by speaking to a public official who has taken on the task of communicating that risk to the public in their name. When we release scientists from their duty to communicate the conclusions of their risk analysis to nonexperts under the supposition that their responsibility ends in the technical sphere, we are left with a dangerous gap between science and the public that can have disastrous results. We also agree with Miller that "an ethos of expertise-that is, an ethos grounded not in moral values or goodwill, or even in practical judgment, but rather in a narrow technical knowledge" tends to accompany the separation of technical sphere risk analysis from public sphere risk communication and does not serve either scientists or the public well. ${ }^{9}$ To earn the trust we invest in them, scientists must draw upon a full rhetorical ethos grounded in moral values (arête), goodwill (eunoia), and practical judgment (phronesis).

Considering how the proper role of scientists is configured in the two judicial decisions on the L'Aquila case, we argue that the first decision interpellated the promising figure of the responsible scientist-as-citizen who is expected to enact public engagement by taking up an integrated rhetorical ethos in communicating with a broader public, or at least correcting inaccurate information communicated to that public in his or her name, whereas the second decision assumed a false distinction between public and technical spheres that inappropriately absolves scientists from responsibility to their fellow citizens and reduces their ethos to an expertise divorced 
from rhetoric. The alienation of scientists from their responsibilities as agents in a broader civic culture comes, as Lynda Walsh puts it, "at the cost

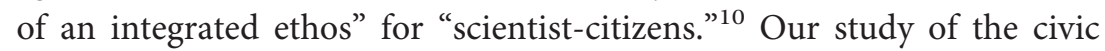
responsibility of the L'Aquila scientists is important because it helps to establish that cost and thereby promotes the constitution of rhetorically sensitive scientist citizens, who, as philosopher Heather Douglas puts it, "have the same obligations as the rest of us not to be reckless or negligent." 11

\section{The Lesson to Be LeARned from L'AQuila}

In establishing the responsibility of scientists to act as members of a broader civic community, this study offers a new understanding of the lesson to be learned from L'Aquila. Many scientists and science journalists who have written about this case have come to two conclusions about what it teaches us, both of which we find problematic. The first lesson that they have drawn from L'Aquila follows from the common misconception that the scientists were prosecuted for failing to predict the earthquake. Tracing out the implications of that assumption, they conclude that the indictment of the scientists and the decision of Judge Billi had a chilling effect on scientists asked to do risk analysis, an effect that can only be reversed by indemnifying future science advisors from lawsuits. As Thomas Jordan, chair of the International Commission on Earthquake Forecasting for Civil Protection, put it, this case "will cast a pall over any attempt to improve" the system for communicating risk to the public because "scientists are learning to keep their mouths shut." 12 One of the main "lessons" to be learned from L'Aquila, he says, is that we "need to separate the role of science advisors" from "that of civil decision-makers" because "misconstruing these roles leads to trouble."13

We think that this is an ironic lesson for people to be taking from this case. Keeping their mouths shut was the very thing that got these scientists into trouble in the first place, so learning to keep their mouths shut seems a particularly perverse conclusion to draw from the case. It is likely that the scientists who met in L'Aquila were silent in the face of misinformation as a direct result of their belief that their job was complete when the risk analysis was done and the separate job of the risk communication and management specialist had begun. Had they recognized that risk analysis includes effective communication of their conclusions with those who hold less expertise 
on the subject, including communication with the public official who was speaking in their name-making sure that he understood the science and was describing it accurately to others-then the people of L'Aquila would not have been misled into thinking that the swarm of earthquakes they were experiencing reduced the likelihood of a larger event.

A second lesson from this case that has been repeated in a number of news outlets is that the scientists erred because they were too close to the politicians, allowing themselves to be used as puppets by officials at the DCP in a sham risk analysis held to support the predetermined outcome of calming the public by reassuring them that the danger was low. Just like those who extracted the previous lesson from this case, these commentators draw the conclusion that to avoid this sort of thing in the future, scientists should do a better job of isolating themselves from politics; they should retreat to the technical sphere where the science of risk analysis can be performed away from the corrupting influence of risk communication and management. ${ }^{14}$

While this interpretation of the scientists as puppets of the government has some truth to it, we think it too ultimately misses the point. The scientists who met in L'Aquila that day likely failed to perform rhetorical citizenship in countering the misconceptions of De Bernardinis and his boss because they saw themselves as separate from politics, not because they were too close to these politicians. We think the scientists in L'Aquila did not overengage in issues relevant to politics and the public sphere; rather, they underengaged by failing to intervene to correct public misrepresentations of their conclusions. Not recognizing that their duty as citizens was to act as whistleblowers against misguided attempts to calm their fellow citizens in the general public, they acted as technical experts only, shutting their mouths when they could not affirm the reassuring energy dissipation theory those politicians wanted to hear, and then with a failure of rhetorical citizenship, washing their hands of the whole affair to retreat to the technical sphere as soon as the meeting was over. Had they acted as scientists who likewise see themselves as citizens, as agents in the public sphere with a responsibility to their fellow citizens, they would have actively resisted attempts to co-opt their expertise for inaccurate messages of reassurance.

Our own reading of the case offers a lesson that is the opposite of these other two lessons that have been proposed in popular accounts. We think this case shows that scientists need to think of themselves beyond their role 
as analysts isolated and protected in the technical sphere. Our reading also complicates or significantly extends research done by other rhetoricians on this case. In their study of the organizational rhetoric of this case, Emina Herovic, Timothy Sellnow, and Kathryn Anthony argue that the disaster was the result of either "external pressure" on public officials or their "gross misunderstanding of the conclusions provided by the scientists." ${ }^{15}$ Our study suggests that this conclusion lays the blame too completely on the public officials and unfairly lets the scientists off the hook. In their study of the legal rhetoric of this case, Marouf Hasian, Nicholas Paliewicz, and Robert Gehl point out that the L'Aquila scientists “engaged in boundary work that maintained the scientific ethos of seismologists, while absolving them of legal responsibility." 16 Whether or not the scientists are legally culpable, we argue that their boundary work does not absolve them from their ethical responsibilities as members of a polis and paradoxically may have contributed to the tragic outcome of this case. To avoid such tragedies in the future, scientists need to see themselves as simultaneously performing a duty as citizens in the public sphere, with a responsibility borne of their special expertise to communicate the results of their risk analysis with those who do not have that expertise. Our reading of this case aligns with that of Danielle DeVasto, Scott Graham, and Louise Zamparutti, who argue that what was required in this situation was a "true hybrid forum" that brings together experts and laypersons. ${ }^{17}$ But extending their conclusion, we argue that a forum is not enough; scientists have a special responsibility to enact that hybridity in ethical communication in and around that forum to bridge the gap between the technical and public spheres. Our reading also differs from the one offered by DeVasto on her own, insofar as she argues that a promising candidate for the interactional expertise necessary to bridge the gap between expert and layperson was De Bernardinis, whose epic failure to unite technical content and public communication was "most surprising" in this case. ${ }^{18}$ We are not surprised by that failure, because De Bernardinis was not an expert on earthquakes. We argue that the L'Aquila scientists are more promising candidates for bridging technical and public knowledge because they dwell in both spheres.

When the trial was just beginning, argumentation scholar Sally Jackson said that because the six scientists "undoubtedly knew that what De Bernardinis said was false and dangerous," and yet "they did not contradict De Bernardinis, then or later," they may have shirked the "duty of care" that 
they had as experts who are also members of a larger citizenry. After all, "scientific practice is subject to the same moral responsibilities as apply to any other social action." However, when Jackson wrote her study of this case, she was hesitant to pass judgment, because "until the trial is concluded, no one is really in a very good position to say whether anyone failed in their duty of care for the citizenry." ${ }^{19}$ Now that the trial and appeals have concluded, we believe the time has come to review that testimony and pass judgment on the ethics of the scientists' rhetorical acts and failures to act in this case.

De Bernardinis claimed in the trial that he did not know that the energy dissipation theory he had heard was wrong. During the first trial, he stated that had he known, he never would have disseminated that theory to the public. ${ }^{20}$ Only the scientists had the expertise to correct his faulty statements. That is why we cannot accept the conclusion that scientists should leave the risk communication to government officials or communication professionals. Risk communication is an essential part of risk analysis; the two cannot be separated because risk analysis that is not communicated to the public or to an intermediary who can pass it on to the public is impotent. We think an important lesson to take from this case is that scientists should come to see themselves as scientist citizens, with a responsibility to analyze the data, yes, but also a responsibility to effectively communicate the results of that analysis to those who need to know it; and to do that, they must take up a rhetorical ethos that not only displays technical expertise but also demonstrates virtue, goodwill, and good judgment to communicate their specialized knowledge with people who do not already share it.

The sense of rhetorical ethos that we invoke in this study of the L'Aquila case encourages the development of habits of character that are oriented toward the common good, so that to take up this ethos is to perform it, not merely seem to do so. ${ }^{21}$ It draws from the Ciceronian idea that a person's various roles in life have corresponding officia (duties), and that rhetorical activities are "social responsibilities through which the community and the polity are sustained and enriched." ${ }^{22}$ The sense of rhetorical citizenship that we invoke sees public participation in discourse as central to what it means to be a citizen. ${ }^{23}$ We draw on Robert Asen's “discourse theory of citizenship" that "conceives of citizenship as a mode of public engagement." As Kock and Villadsen put it, "discourse that takes place between citizens is arguably more basic to what it means to be a citizen" than legal rights, 
privileges, and material conditions. Because "citizenship inherently has a rhetorical side," there is a need for rhetorical scholars to perform grounded criticism to identify the "ruling discursive norms" in particular cases, norms that, "whether they are recognized or not," and though they are sometimes "at odds with more abstract idealizations," serve to guide civic life. The concept of rhetorical citizenship suggests that citizens have "discursive responsibilities or duties." ${ }^{25}$ What those duties entail depends on the contributory potential of the citizens involved. As philosopher Kwame Anthony Appiah reminds us, "because citizens differ in what they have to contribute, there is a great variety of ways of contributing responsibly, as a citizen, to government by the people. ${ }^{26} \mathrm{We}$ argue that when the citizens in question are scientists with knowledge that is needed by their fellow citizens to make good decisions, their rhetorical citizenship duties include public communication drawing on an integrated rhetorical ethos.

\section{SCientists as Citizens}

Sociologists Alan Irwin and Brian Wynne noted over 20 years ago the pressing importance of studying "the relationship between scientific expertise and the 'general public." 27 Attention to this concern continues to this day, especially among those who study the relationship between science and politics in democratic societies. Consider, for example, Sheila Jasanoff s call to sweep away "simplistic theoretical models of science-society relations" and recalibrate "the relations between science and its multiple publics." ${ }^{28}$ Especially when it comes to risk regulation, the need "for a new relationship between science and the public" has become something of a commonplace in such studies, where proposals for new models of "Postnormal Science" and "Citizen Science" are advanced to negotiate "new relations between expertise and citizens." 29

Given the importance of this line of research, it is unfortunate that those offering such proposals tend to advocate only one way to heal the disconnect between science and citizens-namely, empowering citizens to enter the province of science. As a case in point, consider risk communication scholar Rolf Lidskog's review of the literature on "the expert-lay divide," from which he concludes that all recent proposals to overcome the divide "advocate inclusive strategies within knowledge production: that citizens should not only be seen as passive receivers of scientific knowledge, but also 
as active partners in the production of knowledge." Agreeing with these recent proposals, he concludes that "earlier demarcations between science and laypeople should be transgressed through a democratisation of science and a scientisation of the citizenry." 30 The sensible chiasmus of this statement implies that each side-science and the public-must step out of its isolated sphere to meet in the overlapping middle space. Lidskog encourages this interpretation with a metaphor that envisions scientists swimming downstream and the public swimming upstream. But we think a closer look at recent proposals for resolving the expert-lay divide reveals that another metaphor might be more apt. Models of postnormal science and citizen science are designed to encourage movement of one party across a border; they are pleas for "public inclusion" that urge scientists to open the gates of their expert domain to the public and invite the public to swim up to enter that previously forbidding realm. Lidskog's summary fits well with this border-opening metaphor. "In short, science has to humanise itself by bringing people back into science and by making explicit its basic assumptions, value-laden decisions, and practical implications. The public, in turn, has to scientise itself by using its reflexive capacity to critically evaluate science and produce knowledge of relevance to the understanding of environmental risks." ${ }^{31}$ In each case, the public is rightly encouraged to enter the technical sphere of science; however, scientists are not explicitly encouraged to cross the border between spheres to embrace their role as citizens in the public sphere. The democratization and humanization of science that Lidskog describes is the opening of the erstwhile tightly controlled territory of science to the public, not a recognition of the citizenship responsibilities of scientists. $^{32}$

This imbalance is noteworthy because Lidskog begins his study of the expert-lay divide with two narratives that illustrate the difficulties that arise when scientists fail to accept their responsibility as public rhetors. In the first, we are told that "plunderers sold barrels for two dollars each to the inhabitants of an Iraqi community," only to have it later "revealed that the barrels originated from an Iraqi nuclear research centre and its waste plant" where they had been used to store yellow cake. The local people who bought the barrels and used them to wash clothes and store food "had no information that the barrels were contaminated" and were bewildered when their children became sick. In the second case, a woman in a village near the Chernobyl catastrophe relates her experience with an expert who offered 
advice on how to cope with the fallout: "along came some pompous idiot of a scientist and gave a talk to the village club and said we had to wash the firewood... . You couldn't believe your ears." ${ }^{\text {"33 }}$ The clumsy communication of this scientist struck the villagers as running so counter to common sense that it was dismissed out of hand.

Lidskog initially concludes that "both these stories are examples of how difficult it can be for laypeople to understand expert advice aiming to protect them from certain risks," but then later he suggests that such a reading is wrong, because "to reduce these stories to only being a problem of risk communication would mean adopting the 'deficit model' of public understanding of science." Like most scholars studying science and society today, he rejects this model as an elitist attack on the intelligence of citizens; after all, it is often the case that "expert claims are ignored by citizens not because they are incomprehensible, but because they are deliberately rejected." ${ }^{34}$ We agree with Lidskog that the deficit model is misguided, but we do not think that identifying these cases as a problem of risk communication requires adopting that model. In fact, neither of Lidskog's interpretations of these stories seems to fully capture the lesson they offer. In the first case, the failure of Iraqi nuclear scientists to recognize their responsibility to those outside their facility, a duty to clearly mark the barrels as contaminated, resulted in a total lack of communication on their part, not a failure on the part of laypeople to understand expert advice, nor a deliberate rejection of such advice by laypeople. Scientists demonstrated a lack of goodwill and practical knowledge by placing deadly material in unmarked barrels. Likewise, the tragedy of the expert-lay divide in the Chernobyl case had more to do with a failure of scientists to act as public rhetors demonstrating good judgment than with either laypeople's cognitive deficiencies or their thoughtful critical rejection of expert advice. Both cases are classic examples of scientists failing to enact their role as citizens with good rhetorical ethos in the public sphere; tragedy resulted when they neglected their responsibility to effectively communicate what they knew to be a risk to their fellow citizens.

In our view, the problem with the widely disdained deficit model is not just that it underestimates the intellectual capacity of nonexperts but that it assumes that the fault of the deficit lies on the public, and that if laypeople could just be better educated, their minds would fill with the sustenance of scientific knowledge, and the expert-lay divide would be safely bridged. As 
much as they reject the deficit model, many scholarly proposals for "public inclusion" that bring citizens into science carry some residue of the assumption that if the public could just be educated about science, the deficiency separating science and the public would disappear. But what if the problem is not the failure of laypeople to understand or participate in science, but the failure of scientists to understand or participate in the public sphere? Arguments that we develop a postnormal science that brings extended peer communities into the assessment of risk, or that we remake members of the general public into practitioners of citizen science, are arguments that laypeople be brought into the technical sphere. ${ }^{35}$ But such cases as the ones that Lidskog introduces suggest that there are times when a solution to the tragedy of the expert-lay divide lies not in democratizing science or scientizing the public but in bringing scientists out of their isolation in the technical sphere so that they can embrace their rhetorical duty as citizens to speak to their fellow citizens in the public sphere with arête, eunoia, and phronesis. Our analysis of the L'Aquila case illustrates this most clearly.

\section{Context for the CASE: Public UnRest in L'AQUila}

On March 30, 2009, one week before a massive earthquake hit L'Aquila, the Italian DCP Head Guido Bertolaso designated De Bernardinis, a former professor of hydraulic engineering and his vice-head, as his substitute public official in charge of leading a special gathering of the MRC in L'Aquila. On that day, Bertolaso sent out letters of convocation to the leading Italian experts in seismology, explaining to them that the goal of the special MRC meeting in Abruzzo was to conduct "a careful investigation of the matters of science and matters of civil protection related to the seismic sequence of the last four months that is ongoing in the territory of L'Aquila, and that culminated in a shock of magnitude 4.0 on March 30, 2009, at 3:38pm." ${ }^{36}$ That same day, the DCP also released a public statement to the local press, announcing the MRC event planned for the following day and clarifying to the local public that such a special meeting in town had specifically the goal of providing the citizens with scientific information about the swarm of earthquakes they had been experiencing. ${ }^{37}$

L'Aquila, the capital of the Abruzzo region in central Italy, is a town with a long history of destructive earthquakes. After the shock of March 30, and the alarms about an impending destructive earthquake spread by a retired 
technician of the National Institute of Nuclear Physics and amateur "seismic researcher" named Giampaolo Giuliani, the local residents appeared more preoccupied than ever. ${ }^{38}$ In that period, many had been spending their nights sleeping in their cars, enacting the local cautionary habit of getting outside of potentially dangerous buildings in moments of perceived high seismicity, a folkloric custom that the locals had been following for generations as a way of protecting themselves and their families in periods of heightened seismic risk, such as after moderately high-magnitude shocks. At the end of March, the perceived seismic danger in L'Aquila had reached its peak because of the incessant and intense seismic swarm but also because of Giuliani's alarms. The residents' interest in Giuliani's catastrophic predictions-which he based on elevated radon gas readings along fault lines and disseminated locally via word of mouth and social media even after having been sued by the DCP for spreading false alarms-grew proportionally with the increased frequency and magnitude of the seismic swarm. Given the situation of general fear and public unrest, the local and national authorities intervened with the intent of reestablishing public order and safeguarding public safety.

\section{The Major Risks Commission Meeting in L'Aouila AND ITS AfTERMATH}

In this context, on March 31, 2009, six of the top Italian scientists with expertise in earthquakes convened in L'Aquila to attend the extraordinary MRC meeting. The six participants were Franco Barberi, a volcanologist at the University of Rome "Roma Tre" and a former president of the DCP and vice president of the MRC at the time of the facts; Enzo Boschi, Director of the National Institute of Geophysics and Volcanology (INGV) in Rome; Gian Michele Calvi, director of the European Centre for Training and Research in Earthquake Engineering in Pavia; Mauro Dolce, head of the seismic-risk office of the DCP in Rome; Claudio Eva, a professor of earth physics at the University of Genoa; and Giulio Selvaggi, director of the INGV's National Earthquake Centre in Rome. ${ }^{39}$ The experts discussed the ongoing seismic swarm, responded to questions about the risks associated with the frequent seismic events that had generated the situation of local public alarm, and reviewed the available data about the territory and its structural vulnerabilities. Such local authorities as the Mayor of L'Aquila 
Massimo Cialente, the local DCP officer Daniela Stati, and a few others also attended the event to gather accurate data from the experts.

In the local context of panic and confusion in L'Aquila, the MRC meeting was perceived as the chance to get an official answer to a question that only science could address at that point: both the local residents and the authorities in L'Aquila needed credible information to understand whether they were in a moment of increased seismic risk. They also needed expert advice about the appropriate actions and preventive measures to enact for public safety.

\section{THE MRC'S RISK ASSESSMENT}

During the meeting, the scientists provided an overview of the seismic data available about the Abruzzo area and focused on defending their stance about the impossibility of predicting earthquakes against Giuliani's alleged ability to make reliable quake predictions with a margin of a few hours of anticipation of a seismic event. During the discussion, Boschi observed: "It is improbable that there will be an earthquake like the [massive] 1703 one in the short term, although we cannot exclude it in the absolute." Barberi also emphasized the unreliability of predictions in seismic science. Eva observed that of the many seismic sequences recorded in Italy in the last few years, none had anticipated strong seismic events. However, Eva added: "obviously, L'Aquila being a seismic zone, it is not possible to state that there won't be earthquakes." Boschi continued the assessment, explaining that many small shocks should not be seen as a precursor phenomenon for big earthquakes and that "it is impossible to make predictions." He also added: "L'Aquila's territory is in a seismic zone of Level 2, and thus it requires particular attention for the buildings, which need to be reinforced in order to be resistant to earthquakes." In agreement with this assessment, Selvaggi and Barberi supported the idea that a seismic sequence is not a reliable predictor of destructive earthquakes. Finally Barberi, prompted by the local DCP officer Daniela Stati-who had asked for clarification about the reliability of the statements of "whoever affirms to be able to make predictions" (namely, Giuliani) - answered, in no uncertain terms, "Today we have no instruments to make predictions, and therefore every prediction has no scientific credential." 40 
Upon review, the discussion reported in the official MRC minutes cannot be interpreted as having a reassuring tone or content. The official minutes are a brief summary of the MRC meeting, mostly revolving around the nonpredictability of earthquakes supported by a short discussion of seismic swarms that, according to the experts, may or may not precede a major seismic event and therefore are not to be considered as a reliable precursor to strong earthquake shocks. ${ }^{41}$ In the official minutes of the meeting, we see that the scientists used mostly hedged statements, defending uncertainty in the face of the deterministic pseudoscientific predictions of the local self-professed expert. It is important to highlight this dispute between mainstream science and Giuliani that was weaved into the discussions of the experts during the MRC meeting of March 31. Because of Giuliani's popularity and the alarm that his predictions had caused among the Aquilani, the MRC meeting became a venue to defend the authority of the experts in terms of evaluation of seismic risk against Giuliani's unorthodox method of earthquake prediction based on measurement of radon gas. The preoccupation with Giuliani's predictions during the meeting created a rhetorical situation in which the scientists, pressured by the DCP to speak about the technical question of the scientific predictability of earthquakes, missed some important opportunities to use their expertise to rectify a different and more dangerous kind of flawed information that ended up circulating in the public sphere: namely, the information about the supposed positive effect of seismic swarms reported to the public in their name by the DCP after their meeting in L'Aquila.

De Bernardinis's public communication debacle in L'Aquila happened because the experts neglected to ensure during the meeting that the laypeople in attendance-including De Bernardinis and such local authorities as the mayor of L'Aquila and Stati-correctly understood the discussion of the expert participants. By neglecting to ensure that the local authorities and the DCP government officials accurately understood the data that they presented on that occasion and by failing to correct a flawed interpretation of their findings that was reported to the public in their name by De Bernardinis, they sanctioned that flawed interpretation, leaving it to circulate uncorrected in the public sphere. Most importantly, because De Bernardinis acted as the official spokesperson for the MRC after the meeting in L'Aquila, the public perceived the information he reported as scientific, reliable, and coming directly from the scientists-while in reality it was 
inaccurate and just as pseudoscientific as Giuliani's alarms that the MRC and the DCP were so invested in debunking.

\section{Missed Opportunity \#1-Seismic Swarms "Ironically" Posited as Positive "ENERGY DisSIPATION"}

The official version of the MRC minutes was prepared by Dolce and only undersigned by the other MRC experts when they gathered again in L'Aquila on the afternoon of April 6-after the earthquake disaster had already occurred. However, the existence of an earlier and different version of those minutes, written by Lorella Salvatori, a DCP employee in charge of taking notes during the MRC meeting, was discussed at length during the trial. Salvatori testified that the notes she took on that day for the DCP carefully reported the discussions of the experts as they evolved during the meeting of March 31 in L'Aquila. Salvatori's draft of the minutes is six pages long (the official minutes are only a one-page summary of the main themes discussed), and they are mostly consistent with the official version signed by the scientists that had been drafted and polished by Dolce. However, a significant difference surfaced during the trial: Salvatori's version includes a quote that was not included in Dolce's minutes. This passage reports that Barberi asks the other experts to comment on Bertolaso's view of frequent small earthquake shocks as a favorable dissipation of energy from underground. This flawed interpretation was not debunked during the MRC meeting, and it was later communicated to the local public by De Bernardinis.

Salvatori's account reports that during the meeting, Barberi posed the question to the other experts in these terms:

(BARBERI): We know that Abruzzo is a high-risk seismic region. When there have been major earthquakes in the past, there have also been seismic sequences similar to those that are happening today. What can you say about this? I have heard the Head of the DCP declaring to the press, even if he's not a geophysicist, that when there are frequent seismic sequences there is a dissipation of energy that makes it more possible for a strong shock to not happen. What can you say about this? ${ }^{42}$

A more explicit statement of the energy dissipation theory can hardly be imagined. According to Salvatori's draft minutes, Eva's response, which 
also appears in the official minutes, does not directly answer the question but instead notes the lack of recorded data from the past seismic sequences of Abruzzo and the known seismicity of L'Aquila that makes it "impossible to state that there won't be earthquakes." ${ }^{3}$ The omission of Barberi's question about the flawed "energy dissipation" statement of DCP Head Bertolaso in Dolce's official version of minutes and the lack of an unambiguous answer to that question from the experts present on that occasion was discussed in the first MRC trial. The experts had contradictory memories about this point: one scientist recalls the question but others do not. Selvaggi, for example, stated confidently that he did not remember hearing it during the meeting, saying: "I dissent strongly from the concept that the seismic sequence dissipated energy and that it was to be considered as a favorable sign: I never supported such an interpretation, and this theme was never mentioned during the meeting." ${ }^{44}$ Selvaggi even said that a concept like that would have made him "jump on his chair." ${ }^{45}$ Another expert seemed to think that the ensuing conversation about lack of information about past seismic swarms was the best follow-up to Barberi's questions and did not feel the need to more thoroughly debunk Bertolaso's views reported by Barberi. In his testimony, in fact, Eva declared that his words were fairly reported in both versions of the minutes, and that he felt completely comfortable signing them at the time. However, he insisted that his statements needed to be contextualized and understood as an intervention related to the larger conversation about seismic swarms introduced by Boschi and Selvaggi at the outset of the meeting rather than a direct response to Barberi's debated questions. In fact, he clearly stated: "I dissent strongly with the idea that the seismic sequence was dissipating seismic energy and thus it could be interpreted as a favorable sign. That proposition is scientifically flawed." ${ }^{46}$ During the trial, Salvatori was also questioned about her notes from the meeting, specifically about Barberi's mention of Bertolaso's "energy dissipation" interpretation, and she explained that the question had been indeed asked during the meeting by Barberi. She confirmed that "the term 'energy dissipation' was never mentioned again during that meeting. The discussion shifted to discussing the seismic sequence." $^{47}$

Barberi himself declared in the trial that he did not remember with precision what he said, but at the same time he suspected that if he actually had uttered that question-as the unofficial draft of the minutes of the 
meeting suggests-he must had done so with subtle irony. He declared in court:

(BARBERI): I would like to add that my statement there was also a bit ironic, as I had heard the head of the DCP declare to the press, even though he is not a geophysicist, that when there are more frequent seismic sequences they dissipate energy and there are more probabilities that the strong one does not happen, so I asked what they could say about it? That's the sense of this discourse. $^{48}$

From this testimony, it seems likely that the interpretation of the ongoing shocks as positive "energy dissipation" did appear during the meeting, in the words of Barberi reporting on Bertolaso's statement. We also learn that Barberi's question was not answered directly during the experts' discussion, possibly because Barberi was using a bit of irony asking it, or just because the rest of the discussion about seismic swarms seemed sufficient to implicitly debunk Bertolaso's interpretation without the need of further response to something that the head of the DCP had mentioned in public but that they found ridiculous and thus not worthy of attention or discussion.

Barberi's use of irony when posing this question to the group of expertsand the experts' neglect in answering that question in an accessible way for the laypeople in attendance to understand that such an interpretation of the ongoing seismic sequence was wrong-showcases a failure of goodwill and good judgment on the part of the scientists. Not taking this topic seriously during a meeting that laypeople were attending to gather accurate information to report to the broader public represented a serious error in orientation toward that nonexpert audience, because making fun of Bertolaso's interpretation not only mocks laypeople for believing unscientific balderdash but also fails them by not correcting that flawed interpretation of the science. The consequence of this lack of goodwill toward the nonexpert audience in L'Aquila, namely, leaving "scientifically flawed information" uncorrected in front of the local authorities who needed to understand it, also points to a failure of practical wisdom in their public discourse. Inaccurate information conveyed to the nonexpert audience jeopardized the goals of the MRC meeting and consequently public safety. A simple clarification by the experts of the lack of scientific validity of Bertolaso's "energy dissipation" interpretation of the seismic swarms could have prevented the 
further dissemination of that flawed interpretation to the public during the press release and televised interviews that followed the MRC meeting. In neglecting to publicly debunk a flawed interpretation of the seismic phenomena during an ad hoc MRC meeting organized to provide the public with the most accurate information about the ongoing seismic risk in L'Aquila, the experts missed the first key opportunity to enact rhetorical citizenship and prevent the circulation of flawed scientific information, thus increasing rather than reducing the local residents' exposure to seismic risk when the major earthquake hit the town just five days after the meeting.

\section{Missed Opportunity \#2-Daniela Stati's Misunderstanding of the MRC'S Risk Assessment as "Reassuring" Goes Uncorrected at the Conclusion of the MeEting}

Another salient missed opportunity to correct the flawed interpretation of nonexperts that would be communicated to the public occurred at the end of the meeting. According to Salvatori, the local DCP officer Stati declared to the experts: "Thank you very much for your assessment that will allow me to go out there and reassure the population via the media that we will meet during the press conference." ${ }^{49}$ This statement, surprisingly, did not elicit any response from the experts. None of the scientists objected to Stati's view of their findings as "reassuring" or clarified for her that their risk assessment could not be interpreted as a comforting message. Not questioning or debunking the idea that their assessment could be used to "reassure the public via the media" in the following press conference was another missed opportunity for the experts to demonstrate their goodwill toward their fellow citizens by working to protect them from false information. The repeated mentioning of the press conference and the media also suggests that the experts should have had at least some awareness that this assessment would be communicated to the public. In failing to consider the negative consequences of a false reassurance being disseminated by Stati, they also failed again to demonstrate the practical wisdom of citizens drawing upon rhetorical ethos, instead demonstrating a narrow ethos of expertise divorced from civic life.

Salvatori reported that the meeting was dismissed at 7:30 PM, when Stati, the mayor of L'Aquila, De Bernardinis, and Barberi went on to lead a press 
conference with another two public officials of the DCP. When questioned about her statement at the end of the MRC meeting, Stati declared that during the MRC discussion she had heard with certainty that the seismic swarm was favorable because it allowed a continuous dissipation of seismic energy. Stati remembers having heard this interpretation of the swarm from one of the experts; she did not remember clearly which one of them uttered those words, but she clearly remembered hearing those words and that the statement was not contested by anyone present. From the trial testimony and documents, we learn that those words were probably uttered by Barberi with an ironic connotation that Stati did not catch. None of the experts intervened to debunk the flawed interpretation attributed to Bertolaso by Barberi, thus reinforcing the misunderstanding of the local authorities in attendance who were not equipped to detect Barberi's subtle irony nor process the very technical assessment of the seismic swarm that followed Barberi's question. In fact, Stati during the trial testimony explained her misunderstanding as follows, reporting what she remembered from the day of the meeting:

(STATI): I remember that I asked several times, after the statements of the experts, like Prof. Boschi. ... I just want to say once again: I am not an expert. I was told that we could do this press release, they talked about details, they said.... I don't remember exactly who said that, that these shocks that preceded ... That it was not sure that these shocks could be a precursor to a big seismic event, exactly because they were dissipating energy, thus preventing the accumulation of energy in the underground and a series of things were said. My questions were not technical, I want to state this once again: I was only concerned about what to say to the journalists out there. My question was validated by the sense of calm from De Bernardinis and the other people present that told me I could reassure the public. ${ }^{50}$

When questioned by the prosecutor during the first trial, she confirmed once again:

(STATI): I remember that more or less everyone had said on that occasion what I explained earlier, namely that the small shocks were just dissipating energy from the underground. I remember that it had been said, but I can't remember who said that exactly, that these small shocks that we were 
perceiving were shocks that were dissipating energy and that this could be considered a seismic swarm, a series of sequences of shocks, one after the other, that were not to be considered precursors of a big one. ${ }^{51}$

A posteriori, we realize that Stati misunderstood the discussions of the experts and took their silence at the end of the meeting as an endorsement of her interpretation. Stati reported that she was worried about what to say to the journalists and the public and that she had asked for the validation of the experts several times, but none of them intervened to make sure that she understood correctly what to report to the public. Most notably, she thanked the entire group in attendance during the meeting for having provided reassuring information to communicate during the upcoming press conference-as carefully reported by Salvatori in the conclusion of the draft minutes of the MRC meeting-and once again none of the experts intervened to clarify that none of the information they had discussed during that meeting could be interpreted as reassuring. Had they done so, they could have prevented Stati's misunderstanding from being spread to the public.

Missed Opportunity \#3-De Bernardinis: Risk Communication Gone WRONG

The popularizer of Bertolaso's flawed interpretation of the seismic swarm as "energy dissipation" was primarily DCP Vice-Head De Bernardinis: on May 31, 2009, he talked to the press before the MRC meeting-recording a video interview that was televised that evening-and led a press conference after the MRC meeting. On both occasions, De Bernardinis's public communication turned out to be not only problematic in style but above all inaccurate in content.

Even before the MRC meeting with the scientists, De Bernardinis recorded a video interview for a local TV station that conveyed an unwarranted message of reassurance to the local public. When questioned during the trial proceedings, the scientists clearly identified the information conveyed by De Bernardinis as "surprising," "not agreed upon," and "scientifically flawed." 52 He communicated to the residents of L'Aquila a public message that we can sum up as follows: according to the scientists, he 
confidently remarked, there was nothing exceptional or new to worry about. He reported that the experts saw the ongoing seismic swarm as indicative of a "favorable situation" as it signaled a gradual "dissipation" of seismic energy that posed "no danger" to the local population because the related events were not strong enough to damage the buildings in town and because the seismic events, he also implied, were "dissipating seismic energy" from the underground, thus preventing the possibility of a big earthquake. Responding to a journalist who asked De Bernardinis about the potential danger of the ongoing shocks, he declared:

(DE BERNARDINIS): There is no danger. I told the Mayor of Sulmona that the scientific community keeps confirming to me that, on the contrary, this is a favorable situation because there is a continuous dissipation of energy ... thus we did see some serious events, but they're not too intense, and in fact so far we have had just minor damage. ${ }^{53}$

De Bernardinis also said on that occasion that the local residents should consider the seismic swarm a normal phenomenon for the territory, suggesting that it was time to relax and let go of the primal fear of a destructive earthquake. When prompted by the same journalist, he suggested that the local residents should stop worrying about the unjustified alarms circulating around town (namely, Giuliani's alarms), go back to their houses (instead of sleeping outside in fear, as they had been doing for a while), and have a glass of good local red wine:

(JOURNALIST): And in the meantime, shall we drink a good glass of wine from Ofena?

(DE BERNARDINIS): Absolutely, absolutely, have a glass of D.O.C. Montepulciano wine: this is important! ${ }^{54}$

Leading the press conference that followed the MRC meeting that afternoon, acting de facto as the spokesperson for the group of MRC experts, De Bernardinis repeated that same flawed message that he had already conveyed in his short televised interview from earlier in the day. The video of the press conference that was used in court has no audio, but the trial testimony of those who attended confirmed that the message communicated by De Bernardinis was essentially identical to the one of his earlier 
video interview: expressing the idea that the seismic swarm posed no danger because it dissipated energy, reducing the odds of larger shocks. In one of the few video fragments of the press conference for which the audio was recovered, we also hear De Bernardinis adding another scientific inaccuracy regarding the seismic swarm that once again demonstrates his misunderstanding of the science discussed during the meeting. He said: "The seismic swarm can last quite a bit. It could have an extended length, but we do not expect an increase in magnitude of the seismic events." 55 None of the experts had expressed this concept in the deterministic terms that De Bernardinis reported.

Examining the video of the press conference led by De Bernardinis and reading the testimony of all the participants during the MRC trial, we find that even more surprising than the inaccurate information that was being communicated on that occasion is that no MRC expert stood up to correct that flawed set of statements. Three of the six earthquake experts who attended the MRC meeting were also at the press conference in which De Bernardinis spoke to the public. In the press conference video that was used in court, we see Barberi sitting next to De Bernardinis in the panel of speakers for the press conference that included (from left to right) Barberi, De Bernardinis, and Stati. As a speaker on the panel, Barberi had an opportunity, not only as a member of the MRC but also as a scientist citizen, to correct the misinformation that De Bernardinis conveyed, but he chose not to. Furthermore, in that same video of the press conference, we also see Dolce and Calvi sitting in the back of the room during the event, attending without speaking to the public or intervening in the discussion. Like Barberi, Dolce and Calvi never intervened to rectify, clarify, or elaborate on De Bernardinis's statements. They did not speak up to correct the errors in interpretation of De Bernardinis and Stati, not in the context of the meeting, as illustrated earlier, and not even when they heard the flawed statements being communicated in public. When interrogated about his presence during the press conference, Calvi said that he had no memories of it, and that he could say that he was there only because he was visible on the video of that event: "I did not actively participate in the press conference, from the point of view of communicating information. I can tell that I was there, obviously, because I'm visible in the video." ${ }^{56}$ Attending the official press conference with De Bernardinis without correcting him validated what he 
was saying in the eyes of the public by conveying their tacit assent of his disastrously reassuring statements.

The official remarks released to the local media during the press conference by De Bernardinis-reinforced by the presence of three of the six experts involved in the MRC meeting (Barberi, Calvi, and Dolce)convinced the local public that it was wiser and more reasonable to remain indoors despite the known vulnerability of many local buildings and the continuous shocks of the seismic swarm. In the context of this press conference, the earthquake scientists' embodied expertise made a silent but powerful argument that De Bernardinis was communicating accurately what they had just said in the MRC meeting. Unfortunately, we know that this is not true and that De Bernardinis's communication was highly problematic.

During the trial, the other three defendants admitted that the right thing to do on this occasion would have been to interrupt the press conference to correct the misinformation being conveyed. Boschi, for instance, stated during the trial that not only did he not know about the press conference but also that he was shocked when, after the big earthquake, he discovered what was said on that occasion. Specifically, he declared that he was outraged by "what was being communicated to the journalists" and by the "modalities and contents of the communication to the media," especially because those contents and modalities "had not mutually been agreed upon, in any way, during the meeting." ${ }^{\prime 57}$ Similarly, Eva, who also did not participate in the press conference, said that he did not know about it. "Had I been there I would have contested the content of the information being communicated. I would have dissented, or at least I would have brought up some scientific corrections." ${ }^{\text {} 58}$ Selvaggi also later distanced himself from the contents of the press conference, saying "I did not know about the press conference, and I did not contribute, in any way, to what had been communicated during that conference. I am extraneous to those public declarations." He also recorded his "dissent on the opinion that the seismic sequence could be considered normal, because we cannot express a judgment of what is the norm for the numerous seismic sequences that happen in the Appennines." ${ }^{29}$

The concerning point of this communication debacle is that although all the experts agreed, during the trial, about the dangerous flaws in the content of De Bernardinis's statements, they either did not bother to pay attention to the public communication that came out of their meeting in the days 
immediately following it, or they were at the press conference but did not intervene even though their words were being misrepresented and reported with a disastrously reassuring connotation.

During the trial, De Bernardinis repeated several times that he would not have talked in those terms if someone had corrected him. In response to a question about whether he knew that seismic swarms could precede a larger earthquake, rather than dissipate seismic energy, he said in court:

(DE BERNARDINIS): No one told me that there were precursors. I am a hydraulic engineer, more specifically my expertise is in fluid mechanics.... I had full trust and complete loyalty in the experts.... they did not tell me anything different. ${ }^{60}$

The energy dissipation theory might have made perfect sense to a hydraulic engineer. But because that expertise was not relevant to the earthquake science being discussed at the meeting of the MRC, De Bernardinis was acting as a layperson in that context. It was the duty of those with relevant expertise to correct his misunderstanding, either during the meeting itself or after the meeting when he disseminated his inaccurate statements to others in the name of the scientists.

In a particularly tense moment during the MRC trial-when the prosecutor asked Bertolaso to explain the origin of his theory of "energy dissipation"- he responded that in the three months preceding the MRC meeting, he spoke about the seismicity of L'Aquila with major experts in the field.

(BERTOLASO): Regarding those statements about the energy dissipation ... that is not something I made up. During the period of my responsibilities as Head of the DCP, while I was on duty, I said those things hundreds of times to the experts, and not once, Dr. Picuti, not even once.... any scientist worthy of this name has ever corrected me or told me "what are you talking about?"-Not even one of them, before 3:32 a.m. of April 6, 2009, has ever contested my statements. ${ }^{61}$

In this testimony, Bertolaso, an MD with an expertise in public health, claimed that before the tragic events of April 6, no earthquake scientist of those he had consulted in the period leading to the MRC meeting had ever 
bothered correcting his wrong understanding of the character of seismic swarms.

Regarding the public communication of risk of De Bernardinis, the scientists had several opportunities to correct his errors-and Bertolaso's error, too-but they never did. De Bernardinis's disastrous reassurance was not only covered by the local news but was also widely reported by the national news media, including the state TV networks; as documented in the trial, several national newscasts and newspapers talked about the MRC meeting in L'Aquila and its "reassuring" outcome, but even after making the national headlines, no expert intervened to correct the flawed report of their discussion. ${ }^{62}$ By sharing their knowledge with each other during the MRC meeting as if it were a technical sphere discussion only, knowing full well that public officials were overhearing their conversation and would report what they comprehended to the public, the experts failed to perform their duty of rhetorical citizenship in L'Aquila. In a letter that was later published in Science, Boschi argued that risk analysis, not risk communication, was the responsibility of the scientists:

The local CPA is responsible for accurate communication of risk and effective management of emergency situations. I did not disseminate false or imprudent information. My question is: what could I do to avoid conviction? I suppose I should have foreseen the earthquake! ${ }^{63}$

Even if we assume-as Boschi did here-that it was not the scientists' job to communicate directly to the general public, we still find his perspective highly problematic. At the very least, the scientists had the responsibility to communicate the inaccuracy of the energy dissipation theory to the DCP officials and other laypeople responsible for communicating the risk the scientists identified to the broader public and to correct the misunderstanding of both Stati and De Bernardinis when they heard them making inaccurate statements at the meeting and at the press conference, respectively.

Scientists are not just experts: they are also citizens in the public sphere in which their expertise has a serious impact. The residents of L'Aquila, who had been anxiously waiting to receive scientifically reliable information from the experts of the MRC, felt reassured after hearing the media coverage of the press conference reinforced by De Bernardinis's earlier video interview. Because of the link between the seismic swarm and the favorability of 
the situation as claimed by De Bernardinis, many residents of L'Aquila started interpreting the continued shocks as positive signs. They made decisions about what to do based on what they discovered, too late and unironically, to be a "scientifically flawed" message. Many Aquilani who changed their behavior in response to what they had heard on March 31 ended up dying under the rubble of their homes on the morning of the quake of April 6, 2009.

Science cannot predict earthquakes; however, studying this case teaches us that there was something more that the scientists could have done for their fellow citizens in L'Aquila: we have identified at least three missed opportunities pinpointed in the first trial in which they could have intervened in the public conversation about seismic risk, precisely because as fellow citizens in the public sphere they had an ethical and civic duty to correct the flawed information that the DCP had been passing to the residents of L'Aquila in their name. Because of their expertise, the scientists were the only citizens who could have rectified that error. Failing to practice their rhetorical citizenship resulted in disastrous consequences in L'Aquila. Like the scientists in Iraq who failed to clearly mark the barrels that would be storing radioactive waste, or the scientists near Chernobyl who failed to adequately explain why firewood should be washed, the scientists of the MRC demonstrated a lack of goodwill toward their fellow citizens when they responded to a faulty theory about energy dissipation with irony or silence. They exhibited a breakdown of good sense when they failed to correct a public official's faulty conclusion that their risk analysis had been reassuring, and they showed a surfeit of virtue when they failed to correct misinformation that was being passed along to the public in their name.

\section{Reintegrating Technical and Public Spheres: The Rhetorical Citizenship OF SCIENTISTS}

Studying this case in detail by drawing from the trial documents and testimony allowed us to identify the points of articulation in which the communication of science went wrong in L'Aquila. We focused in particular on missed opportunities for the scientists to cross the boundaries of the technical sphere and act as rhetorical citizens oriented toward protecting the public good. Such missed opportunities arose in L'Aquila when scientific information migrated, or failed to migrate, from the technical realm of 
risk assessment in the meeting to the public sphere via institutional risk communication. By identifying those missed opportunities, we want to encourage scientists and experts to think of their role in society as going beyond the mere deployment of their expertise in the technical sphere. The scientists' expertise, when confined to the technical sphere, can be vulnerable to distortion, exploitation, neglect, or misunderstanding in the public sphere.

The burden of bridging the expert-lay divide, as this case demonstrates, cannot be placed on laypeople only. Our analysis of the communication debacle in L'Aquila shows that it is also necessary to reflect on the other side of this relationship: it is necessary to start thinking of experts as rhetorical citizens, too. Bridging the gap between experts and lay citizens is possible when scientists recognize that their professional role does not separate them from the communities in which they dwell. Recognizing that they also are citizens within the public sphere-citizens endowed with a special agency derived from their technical knowledge, who also have the ethical responsibility to communicate that expertise when it is salient to do so for the public good-can help to eliminate the gap between experts and lay publics.

Encouraging scientists to recognize that they exist in and operate across the two spheres, the technical and the public, will increase the chances that they will perform their civic duty of sharing their expertise with those who do not have it. Had the MRC experts identified as scientist citizens with the ethical responsibility to communicate with their fellow citizens in L'Aquila (either by speaking thoughtfully with the designated risk communicator or correcting his inaccurate public statements), they would not have let disastrous reassurances circulate uncorrected in the public sphere. Being accountable for the ways their expertise was used to make decisions about public safety would have meant, in this case, clarifying for the public that they had no reassurances or new information to offer to those who were worried about the seismic shocks in Abruzzo and were trying to decide between sleeping outside, as their precautionary habits prescribed, or returning inside their houses at their own risk.

What happened in L'Aquila was not unique to that case. Similar disastrous breakdowns of communication between technical experts and publics have occurred in the past and will likely arise again in the future. One significant case of failed risk communication that has been studied in depth by rhetoricians is worth recalling at this time. When the U.S. space shuttle 
Challenger exploded on takeoff in 1986, scholars of rhetoric analyzed the failed risk communication between engineers and managers that precipitated the tragedy. They concluded that managers made the fatal decision to launch the spacecraft on that cold day, despite the heightened risk identified by technical experts, because those managers adopted a "prior interpretive framework" that mistakenly read "ambiguous language" from the engineers, and lack of definitive evidence that there would be a catastrophe, as a reassurance that all would go well. ${ }^{64}$ As in the L'Aquila case, "a reluctance to cross role boundaries" kept the engineers from effectively correcting that misinterpretation; even though they had several opportunities to register their opposition to the launch decision, they did not do so because they felt "that it was not their place to do so." ${ }^{\text {65 }}$ As Alan Gross and Art Walzer put it in their analysis of the Challenger case, "Strong role differentiation is a useful but, potentially, a dangerous concept." ${ }^{\text {"66 }}$ Like Gross and Walzer, we ground our judgment of this case in a classical perspective of rhetoric as "an art recoverable in the interest of civitas, of organizations viewed as good citizens. ${ }^{\text {"67 }}$ Just as ethos can refer to both the character of an individual speaker and the character of a larger social structure, such as the "ethos of science," so too does ethical responsibility in such cases lie with both the individual scientists and with science as a profession that too often habituates its practitioners to see themselves as fundamentally and properly separate from the public sphere. By recognizing their responsibility as rhetorical citizens to communicate their specialized knowledge to fellow citizens who lack that knowledge, experts in the technical sphere can embrace their role as scientist citizens with a rhetorical duty of care to ensure that the results of their risk analysis are accurately and effectively conveyed to those in need of that knowledge.

\section{NOTES}

1. Italy v. Major Risks Commission, N. 380/12 R. Sent. (2012), 94. All translations from Italian to English have been made by Pamela Pietrucci.

2. Italy v. Major Risks Commission, N. 380/12 R. Sent. (2012), 1-4. As we will outline later in this paper, the fact that the energy dissipation theory had no scientific validity was conceded by the scientists on trial.

3. The stories of the families of the earthquake victims can be found in the trial transcript, which includes testimony that discusses how the information circulating locally after 
the MRC meeting drastically affected the behavior of the local residents before the main shock of April 6, 2009: Italy v. Major Risks Commission, N. 380/12 R. Sent. (2012), 389-651. For an account of this case from the perspective of the residents of L'Aquila involved in the trial, see Pamela Pietrucci, "Voices from the Seismic Crater in the Trial of the Major Risk Committee: A Local Counternarrative of the 'L'Aquila Seven,"' Interface: A Journal for and about Social Movements 8 (2016): 261-85.

4. “Italy v. Major Risks Commission, N. 3317 R. Sent. (2014)." The decision of the appeals court (Corte D'Appello) made on November 10, 2014 was also confirmed on November 19, 2015 by the Italian Supreme Court (Corte Di Cassazione) that officially ended the judicial cycle for this case.

5. For rhetoricians, the seminal article distinguishing technical and public spheres is G. Thomas Goodnight, “The Personal, Technical, and Public Spheres of Argument: A Speculative Inquiry into the Art of Public Deliberation," Argumentation and Advocacy 18 (1982): 214-27. In this essay, we use these terms in the same sense that Goodnight did.

6. Christian Kock and Lisa S. Villadsen, "Introduction: Citizenship as Rhetorical Practice," in Rhetorical Citizenship and Public Deliberation, ed. Christian Kock and Lisa S. Villadsen (University Park: Penn State University Press, 2012), 5.

7. Kock and Villadsen, "Citizenship as Rhetorical Practice," 4.

8. Carolyn R. Miller, "The Presumptions of Expertise: The Role of Ethos in Risk Analysis," Configurations 11 (2003): 166.

9. Miller, “The Presumptions of Expertise," 201.

10. Lynda Walsh, "Visual Strategies to Integrate Ethos across the 'Is/Ought' Divide in the IPCC's Climate Change 2007: Summary for Policy Makers," Poroi 6, no. 2 (2009): 38.

11. Heather E. Douglas, Science, Policy, and the Value-Free Ideal (Pittsburgh, PA: University of Pittsburgh Press, 2009), 81.

12. Thomas H. Jordan quoted in Edwin Cartlidge, "Prison Terms for L'Aquila Experts Shock Scientists," Science, October 26, 2012, 451.

13. Thomas H. Jordan, "Scapegoat Shocker," New Scientist, September 24, 2011, 35. See also Nicola Nosengo, "L'Aquila Verdict Row Grows," Nature, November 1, 2012, 15-16; and Stephen S. Hall, “At Fault?” Nature, September 15, 2011, 264-69.

14. Massimo Mazzotti, "Seismic Shift: Lessons from the L'Aquila Earthquake Trial," Times Higher Education, October 3, 2013, 38-43; and Ranieri Salvadorini, "Why the American Reconstruction of the 'Major Risks' Trial Is Flawed," Medium, September 22, 2014, https://medium.com/@ranierisalvadorini/why-the-american-reconstruction-ofthemajor-risks-trial-is-flawed-d52c758f9b6f. 
15. Emina Herovic, Timothy L. Sellnow, and Kathryn E. Anthony, "Risk Communication as Interacting Arguments: Viewing the L'Aquila Earthquake Disaster through the Message Convergence Framework," Argumentation and Advocacy 51 (2014): 82.

16. Marouf Hasian Jr., Nicholas S. Paliewicz, and Robert W. Gehl, "Earthquake Controversies, the L'Aquila Trials, and the Argumentative Struggles for both Cultural and Scientific Power," Canadian Journal of Communication 39 (2014): 563.

17. Danielle DeVasto, S. Scott Graham, and Louise Zamparutti, "Stasis and Matters of Concern: The Conviction of the L'Aquila Seven," Journal of Business and Technical Communication 30 (2016): 158.

18. Danielle DeVasto, "Being Expert: L'Aquila and Issues of Inclusion in Science-Policy Decision Making," Social Epistemology 30 (2016): 388.

19. Sally Jackson, "Black Box Arguments and Accountability of Experts to the Public," in Between Scientists and Citizens: Proceedings of a Conference at Iowa State University, June 1-2, 2012, ed. Jean Goodwin (Ames, IA: Great Plains Society for the Study of Argumentation, 2012), 13-14.

20. Italy v. Major Risks Commission, N. 380/12 R. Sent. (2012), 836.

21. See S. Michael Halloran, "Aristotle's Concept of Ethos, or if Not His Somebody Else's," Rhetoric Review 1 (1982): 58-63; and Michael Leff, "Isocrates, Tradition, and the Rhetorical Version of Civic Education," in Isocrates and Civic Education, ed. Takis Poulakos and David Depew (Austin: University of Texas Press, 2004), 235-54.

22. Michele Kennerly, "The Stoic Nature of Early Dramatistic Theory," Advances in the History of Rhetoric 14 (2011): 34, 44-45.

23. Kock and Villadsen, "Citizenship as Rhetorical Practice," 1-2.

24. Robert Asen, “A Discourse Theory of Citizenship," Quarterly Journal of Speech 90 (2004): 191.

25. Christian Kock and Lisa Villadsen, "Introduction. Rhetorical Citizenship as Conceptual Frame: What We Talk About When We Talk About Rhetorical Citizenship," in Contemporary Rhetorical Citizenship, ed. Christian Kock and Lisa Villadsen (Leiden, The Netherlands: Leiden University Press, 2014), 11-14.

26. Kwame Anthony Appiah, “The Democratic Spirit," Daedalus 142 (2013): 215.

27. Alan Irwin and Brian Wynne, "Introduction," in Misunderstanding Science? The Public Reconstruction of Science and Technology, ed. Alan Irwin and Brian Wynne (Cambridge, UK: Cambridge University Press, 1996), 1.

28. Sheila Jasanoff, “A Mirror for Science," Public Understanding of Science 23 (2014): 24.

29. Rolf Lidskog, "Scientised Citizens and Democratised Science: Re-assessing the Expert-Lay Divide," Journal of Risk Research 11 (2008): 69.

30. Lidskog, "Scientised Citizens," 71. 
31. Lidskog, "Scientised Citizens," 79-80.

32. To be fair, when scientists render the expert realm more inviting to the public by making explicit their basic assumptions, value-laden decisions, and practical implications, they are changing their practice in ways that draw on norms of the public sphere. But they are not being asked to actually enter the public sphere to take on their citizenship duties as participating members of that broader public. This is a significant difference that we see between proposals for postnormal science or citizen science and our proposal that scientists recognize themselves as citizens with a duty to contribute to discourse in the public sphere.

33. Lidskog, "Scientised Citizens," 69-70.

34. Lidskog, "Scientised Citizens," 70, 82.

35. Silvio O. Funtowicz and Jerome R. Ravetz, "Science for the Post-Normal Age," Futures 25 (1993): 739-55; and Alan Irwin, "Constructing the Scientific Citizen: Science and Democracy in the Bioscience," Public Understanding of Science 10 (2001): 1-18.

36. Italy v. Major Risks Commission, N. 380/12 R. Sent. (2012), 94.

37. Italy v. Major Risks Commission, N. 380/12 R. Sent. (2012), 93-94.

38. In the last days of March 2009, the media announcement of the upcoming MRC meeting was sharing the local headlines with the news regarding the failure of a prediction of a "disastrous" earthquake that, according to Giuliani, should have occurred in Sulmona (a nearby town, about 40 miles away from L'Aquila) on the afternoon of March 29, 2009. That disastrous earthquake never happened in Sulmona, and Giuliani was sued for having spread a false alarm and was severely reprimanded by the DCP. For more about Giuliani's alarms and the testimonies of the Aquilani, see Antonello Ciccozzi, Parola di Scienza: Il Terremoto Dell'Aquila e la Commissione Grandi Rischi. Un'Analisi Antropologica (Roma: DeriveApprodi, 2013).

39. The six experts and De Bernadinis are often referred to collectively in the literature as the "L'Aquila Seven" because all seven were indicted. However, De Bernardinis did not have expertise in earthquakes; he was participating in the MRC meeting as a government official, so when it came to earthquake risk assessment, he was a layperson, not an expert.

40. Italy v. Major Risks Commission, N. 380/12 R. Sent. (2012), 95.

41. For an account of the controversy about the MRC minutes, see Pietrucci, "Voices from the Seismic Crater," 278.

42. Italy v. Major Risks Commission, N. 380/12 R. Sent. (2012), 101. An earlier version of this translation and of the trial transcript used above also appears in Pietrucci, "Voices from the Seismic Crater," 279.

43. Italy v. Major Risks Commission, N. 380/12 R. Sent. (2012), 101. 
44. PM Memo, Italy v. Major Risks Commission, Proc. Pen. 253/10 R.G. Noti (2011), 213.

45. Italy v. Major Risks Commission, N. 380/12 R. Sent. (2012), 137.

46. PM Memo, Italy v. Major Risks Commission, Proc. Pen. 253/10 R.G. Noti (2011), 219.

47. PM Memo, Italy v. Major Risks Commission, Proc. Pen. 253/10 R.G. Noti (2011), $122-23$.

48. Italy v. Major Risks Commission, N. 380/12 R. Sent. (2012), 141.

49. Italy v. Major Risks Commission, N. 380/12 R. Sent. (2012), 102.

50. PM Memo, Italy v. Major Risks Commission, Proc. Pen. 253/10 R.G. Noti (2011), 112. The fact that she counts De Bernardinis as one of the "experts" in this testimony is significant. De Bernardinis did not have expertise in earthquake science, but in his role as spokesman for the scientists was mistaken as an authority on the matter.

51. PM Memo, Italy v. Major Risks Commission, Proc. Pen. 253/10 R.G. Noti (2011), 112.

52. From the testimony of defendants Eva and Boschi in the prosecutors' memo: PM Memo, Italy v. Major Risks Commission, Proc. Pen. 253/10 R. G. Noto (2011), 219-21.

53. Italy v. Major Risks Commission, N. 380/12 R. Sent. (2012), 268.

54. Italy v. Major Risks Commission, N. 380/12 R. Sent. (2012), 268.

55. "Video Rai.TV_Presa Diretta_Irresponsabili-Presa Diretta Del 20/01/2013," http://www.rai.tv/dl/RaiTV/programmi/media/ContentItem-f91d8def-b397-41cc-86ff$7 b 52 c 24 a 2 d b d . h t m l$. The sentence quoted appears at minute 11:55.

56. "Video Rai.TV." The quoted sentence appears at minute 12:30.

57. PM Memo, Italy v. Major Risks Commission, Proc. Pen. 253/10 R.G. Noti (2011), 221.

58. PM Memo, Italy v. Major Risks Commission, Proc. Pen. 253/10 R.G. Noti (2011), 219.

59. PM Memo, Italy v. Major Risks Commission, Proc. Pen. 253/10 R.G. Noti (2011), 214.

60. Italy v. Major Risks Commission, N. 380/12 R. Sent. (2012), 836.

61. "Video Rai.TV." The sentence quoted appears between minute 23:35 and 25:00. Guido Bertolaso was also indicted for manslaughter and appeared in the parallel trial, "Major Risks Commission II." That trial involved a scandal related to a phone-tapped conversation between Bertolaso and Stati on the day before the MRC meeting in which Bertolaso defined the gathering of scientists in L'Aquila as a "media operation of reassurance" and again mentioned the theory of "energy dissipation." Bertolaso was acquitted on September 30, 2016. "Grandi Rischi, Assolto Bertolaso," ANSA.it, http://www.ansa.it/abruzzo/notizie/2016/09/30/grandi-rischi-oggi-sentenza-bertolaso_ 8d081ffd-2932-410f-b167-1b46cb47270a.html.

62. On the night of the meeting, the 8 PM edition of the main national state TV (TG1 RAI National) newscast reported: "179 shocks since the beginning of the year. The earth shakes in L'Aquila. The experts reassured 'it's just a seismic swarm,' but people are afraid." And: "It is a normal situation for a seismic area like L'Aquila, said the experts. 
No reason to be worried, said the DCP." Similar reports can be found in the Mediaset national networks. For example, the 12:25 PM edition of Studio Aperto on the ITALIA1 network reported: "Earthquake syndrome, but there is no danger. Light shocks are tormenting L'Aquila and Abruzzo. A local volcanologist predicts a catastrophic earthquake: panic among the population. For the DCP there is no danger, the prophet of disasters is sued for spreading false alarms." Italy v. Major Risks Commission, N. 380/12 R. Sent. (2012), 289-90.

63. Enzo Boschi, "L’Aquila’s Aftershocks Shake Scientists," Science, September 27, 2013, 1451.

64. Paul M. Dombrowski, "Can Ethics Be Technologized? Lessons from Challenger, Philosophy, and Rhetoric," IEEE Transactions on Professional Communication 38 (1995): 147; and Dennis S. Gouran, Randy Y. Hirokawa, and Amy E. Martz, "A Critical Analysis of Factors Related to Decisional Processes Involved in the Challenger Disaster," Central States Speech Journal 37 (1986): 131. See also Paul M. Dombrowski, "Challenger and the Social Contingency of Meaning: Two Lessons for the Technical Communication Classroom," Technical Communication Quarterly 1 (1992): 81; and Dennis S. Gouran, “The Failure of Argument in Decisions Leading to the 'Challenger Disaster': A Two-Level Analysis," in Argument and Critical Practices: Proceedings of the Fifth SCA/AFA Conference on Argumentation, ed. Joseph W. Wenzel and John Lyne (Washington, D.C.: National Communication Association, 1987), 440.

65. Gouran, Hirokawa, and Martz, "A Critical Analysis of Factors," 124.

66. Alan G. Gross and Arthur Walzer, "The Challenger Disaster and the Revival of Rhetoric in Organizational Life," Argumentation 11 (1997): 84.

67. Gross and Walzer, “The Challenger Disaster," 88. 